\title{
Preliminary bench experiment study on working parameters of pneumatic seeding mechanism for wheat in rice-wheat rotation areas
}

\author{
Chao Wang ${ }^{1,2}$, Caiyun $\mathrm{Lu}^{1,2}$, Hongwen $\mathrm{Li}^{1,2^{*}}$, Jin $\mathrm{He}^{1,2}$, Qingjie Wang ${ }^{1,2}$, Xiupei Cheng ${ }^{1,2}$ \\ (1. College of Engineering, China Agricultural University, Beijing 100083, China; \\ 2. Agricultural Science Observation and Experiment Station of Arable Land Conservation (Northern Hebei Province), \\ Ministry of Agriculture, Beijing 100083, China)
}

\begin{abstract}
In order to solve the serious problems of soil adhesion and blockage as well as high operating resistance for wheat seeders under the condition of sticky heavy loam clay in rice-wheat rotation area, a new concept of non-contact pneumatic seeding technology that could rip wheat seed into the soil by high pressure accelerating airflow was proposed in this paper. A preliminary bench experiment was conducted and high-speed photography technology was used to study the parameters of wheat pneumatic seeding under five levels $(30 \%, 35 \%, 40 \%, 45 \%$ and $50 \%)$ of soil moisture content for loam clay. Experimental results showed that: wheat seeds could be ripped into soil without damage and acquired varying degrees of germination by way of pneumatic seeding; shooting depth shown a deepening tendency with the increase in shooting velocity, and the value of seeding depth and seeding velocity are closely related to the soil moisture level, which wheat seeds can achieve higher shooting depth with relative lower shooting velocity when the soil moisture content increases continuously; none of wheat seeds could be ripped into the soil with about $2.93 \mathrm{~m} / \mathrm{s}$ shooting velocity that accelerated in the form of free fall, while the shooting velocity that wheat seeds needed in order to be completely ripped into soil with $3 \mathrm{~mm}$ shooting depth were 40$50 \mathrm{~m} / \mathrm{s}$ (30\% soil moisture content), 30-40 m/s (35\% soil moisture content), $20-30 \mathrm{~m} / \mathrm{s}$ ( $40 \%$ soil moisture content), $10-20 \mathrm{~m} / \mathrm{s}$ ( $45 \%$ soil moisture content) and $2.93-10 \mathrm{~m} / \mathrm{s}$ ( $20 \%$ soil moisture content), respectively. The experimental results can provide basic data and technical support for the development of non-contact wheat seeding equipment in rice-wheat rotation area.

Keywords: pneumatic seeding, loam clay, soil adhesion, wheat, high-speed photography

DOI: $10.25165 /$ j.ijabe.20201301.4906
\end{abstract}

Citation: Wang C, Lu C Y, Li H W, He J, Wang Q J, Cheng X P. Preliminary bench experiment study on working parameters of pneumatic seeding mechanism for wheat in rice-wheat rotation areas. Int J Agric \& Biol Eng, 2020; 13(1): 66-72.

\section{Introduction}

Wheat is widely cultivated in the world and the global yields of it are about 730 million tons in 2016/2017, while the production of Chinese wheat (about 130 million tons) ranks second in the world according to the statistics of the United States Department of Agriculture. As one of the main grain production bases in $\mathrm{China}^{[1]}$, rice-wheat rotation areas cover an area of 9 million-13 million hectares ${ }^{[2]}$ that accounting for more than $37 \%$ of the national total wheat growing areas. The growth of wheat is less influenced by limitation of water resources in rice-wheat rotation areas that concentrically distributing in the Yangtze River Basin, with ample sunlight resources, abundant rainfall and high groundwater levels ${ }^{[3]}$, so it has become the Chinese greatest potential region for increasing wheat production ${ }^{[4]}$.

Received date: 2019-01-09 Accepted date: 2019-12-10

Biographies: Chao Wang, PhD candidate, research interests: farm machine and conservation tillage, Email: superwang_999@sina.com; Caiyun Lu, PhD, Associate Professor, research interests: farm machine and conservation tillage, Email: lucaiyun@cau.edu.cn; Jin He, PhD, Professor, research interests: farm machine and conservation tillage, Email: hejin@cau.edu.cn; Qingjie Wang, PhD, Professor, research interests: farm machine and conservation tillage, Email: wangqingjie@cau.edu.cn; Xiupei Cheng, PhD candidate, research interests: farm machine and conservation tillage, Email: chengxiupei7088@163.com.

*Corresponding author: Hongwen $\mathbf{L i}, \mathrm{PhD}$, Professor, research interests: agriculture machine and equipment engineering, and conservation tillage. Mailing Address: College of Engineering, China Agriculture University, No.17, Qinghuadonglu, Haidian District, Beijing 100083, China. Email: lhwen@ cau.edu.cn.
There is a serious wet injury in the rice-wheat rotation field during mechanized sowing stage of wheat because of the sticky heavy loam clay ${ }^{[5]}$, urgent time of crops for rotation and rainy autumn ${ }^{[6]}$, which lead to poor tillage quality, soil adhesion and blockage to agricultural machinery. Influenced by field conditions and cropping patterns, shallow seeding depth ${ }^{[7,8]}$ required by wheat after rice compared with dry-land wheat in northern China. However, it is difficult to achieve high efficiency wheat mechanized seeding in rice-wheat rotation area due to lack of specialized seeders that could adapt the soil conditions of high moisture content and heavy clay texture ${ }^{[9,10]}$. In recent years, Chinese and foreign experts have done extensive research and developed a variety of sowing machines. Through reasonable matching of straw picking and throwing device, strip tillage device and opener, Happy Seeder could sow wheat in a rice stubble field with lower soil moisture content ${ }^{[11]}$. An anti-blocking seeder ${ }^{[12]}$ could reduce soil adhesion to opener and showed stable performance in rice-wheat rotation field. Besides, GBSL-180 seeder with two-axel rotary tillage and stubble cleaning be developed to suit wheat sowing in the high stubble paddy field ${ }^{[13]}$, which double rotary tiller rollers were applied to clean up the seed tape and to crush the clod and straw twice that can reduce some sticking and blocking problems of seeding mechanism. A 2BMFDC-6 half-tillage seeder ${ }^{[14]}$ applied shallow rotary tillage technology of a sowing belt that could further reduce the soil disturbance, and at the same time, part of soil and straw adhering to seed metering device removed by rotary blades.

However, most of the existing wheat planters that widely adopted shallow rotary tillage or active anti-blocking technology 
for rice-wheat rotation field are optimized and improved on the basis of traditional wheat rotary tillage seeders ${ }^{[15]}$. During field work, adhesion and blockage of soil-touching parts such as rotary tillage blades and openers occurred while contacting with sticky heavy loam clay. This contact-seeding technology will lead to an increasein operating resistance and power consumption ${ }^{[16]}$, poor quality of sowing ${ }^{[17]}$ that wheat sown on the soil surface have a strong possibility of bringing about the phenomenon of seed-airing, seedling weakness.

In this research, a new concept of non-contact pneumatic seeding technology that wheat seed ripped into the soil that is finely tilled without straw mulching by high pressure accelerating airflow was proposed. The overall objective was to provide basic data for the development of wheat pneumatic seeders in rice-rotation area. A preliminary bench experiment based on self-developed pneumatic seeding mechanism was used: 1) to acquire the working parameters of pneumatic seeding such as shooting velocity and shooting depth; 2) to obtain the regression between shooting velocity and shooting depth under five different moisture levels of loam clay; 3 ) to evaluate whether the way of pneumatic seeding would damage wheat seeds.

\section{Materials and methods}

\subsection{Pneumatic seeding mechanism}

The experimental device used in this research was a self-developed pneumatic seeding mechanism that was designed according to the principle of gas injection. Figure 1 shows the schematic diagram of its structure, which mainly composed of air tee, accelerating tube, air nozzle, rubber sleeve, etc. When testing, keeping a certain height $\left(H_{G}\right)$ between the bottom of the accelerating tube and the soil surface. High-pressure air that formed a negative air pressure in the air tee and a stable accelerating airflow in the accelerating tube was input from the air nozzle, then ejected from the bottom of the accelerator tube. Wheat seeds were put into from the seed entrance while inhaled rapidly by the negative air pressure, during which the rubber sleeve could avoid seeds damage caused by the collision between wheat seeds and steel nozzles. After being accelerated by the accelerating airflow in accelerator tube that it vertical set with the horizontal plane, $600 \mathrm{~mm}$ long and $10 \mathrm{~mm}$ inner diameter, wheat seeds subsequently were ripped into the soil at a certain shooting velocity. Finally, the high-pressure air transmission is closed to complete a single pneumatic seeding test of wheat seeds.

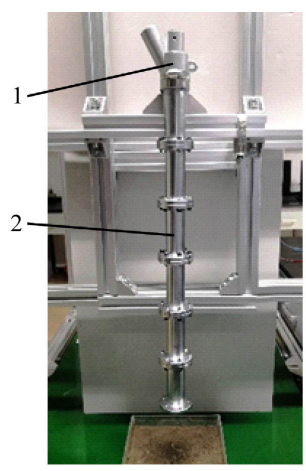

a. Front view

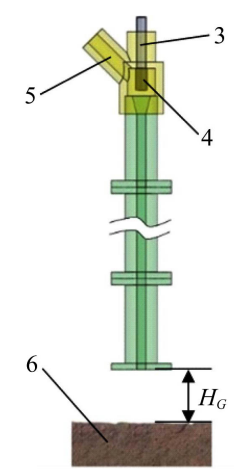

b. Front perspective view
1. Air tee 2. Accelerating tube 3. Air nozzle 4. Rubber sleeve 5. Seed entrance 6. Soil

Note: $H_{G}$ is shooting height, $\mathrm{mm}$.

Figure 1 Structure of pneumatic seeding mechanism

\subsection{Experimental platform}

The main components of wheat pneumatic seeding experimental platform were air compressor, pressure resistant trachea, air pressure regulating device, pneumatic seeding mechanism, rack, experimental soil, 5F01C-16G type high speed camera (designed by Hefei Junda Hi-Tech Information Technology Co., Ltd.), computer and sunlamp, which were shown in Figure 2. Air compressor, air pressure regulating device and pneumatic seeding mechanism were joined together by pressure resistant trachea I and pressure resistant trachea II respectively. During the test, continuous high-pressure air is provided by the air compressor, the accelerating air pressure that ranges from 0 bar to 10 bar in the accelerating tube was controlled by pressure regulating device to realize different shooting velocity of wheat seed. The 5F01C-16G type high speed camera connected with the computer to capture the pneumatic seeding process that wheat seed shooting from the accelerating tube to the soil, sunlamp provides sufficient brightness for this experiment.

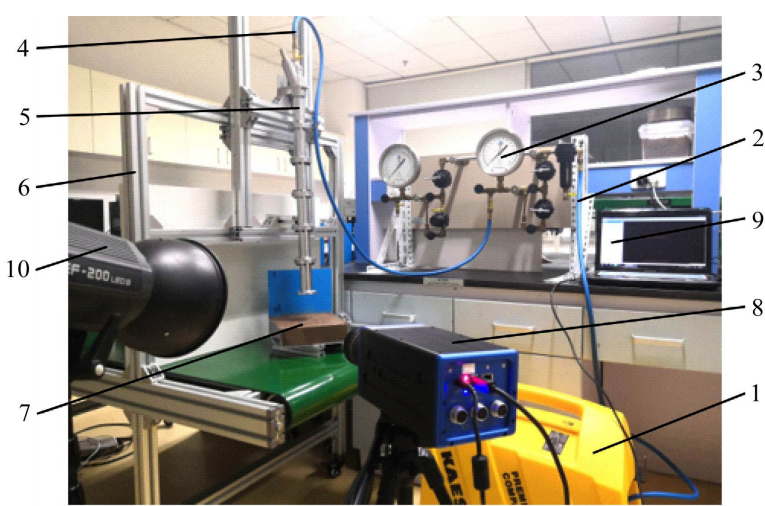

1. Air compressor 2. Pressure resistant trachea I 3. Air pressure regulating mechanism 4. Pressure resistant trachea II 5. Pneumatic seeding device 6. Rack 7. Experimental soil 8. 5F01C-16G type high speed camera 9. Computer 10. Sunlamp

Figure 2 Platform for wheat pneumatic seeding

\subsection{Experimental materials}

The experimental soil samples (0-50 $\mathrm{mm}$ depth) were collected from the experimental plot of Crop Research Institute of Hubei Academy of Agricultural Sciences in Wuhan, Hubei province $\left(114^{\circ} 32^{\prime} 28^{\prime \prime} \mathrm{E}, 30^{\circ} 49^{\prime} 23^{\prime \prime} \mathrm{N}\right)$ on September 2018. Perennial rice-wheat rotation was conducted in this experimental plot, the soil type was loam clay. Soil pH was 6.1, the plastic limit was $23.20 \%$, and the liquid limit was $41.62 \%$. According to China National Standard SL237-1999 "Rules of geotechnical testing",[18] and field soil moisture content of wheat seeding stage ${ }^{[7,10,14,15]}$ in rice-wheat rotation areas, soil samples with five levels of soil moisture content of $30 \%, 35 \%, 40 \%, 45 \%$ and $50 \%$ were obtained for this experiment, respectively, after natural air-drying, impurity removal, grinding and sieving and so on. Five kinds of soils with different moisture content were put into five same self-made square soil tanks $(200 \mathrm{~mm} \times 200 \mathrm{~mm} \times 50 \mathrm{~mm})$ separately, and the soil bulk density of them were controlled at about $1.25 \mathrm{~g} / \mathrm{cm}^{3}$. Finally, the soil with the fresh-keeping film is sealed and kept for testing. Zhengmai 9023, a large-scale planted variety of wheat in Hubei Province, was used for this experiment.

\subsection{Experimental design}

In order to study the working parameters that mainly refers to the relationship between shooting velocity and shooting depth of pneumatic seeding for wheat seeds, preliminary bench experiment was carried out under five levels of soil moisture content: $30 \%$, $35 \%, 40 \%, 45 \%$ and $50 \%$. At each level, six groups of pneumatic seeding experiments were carried out at different pressures of high-speed airflow. Each group of experiments repeated seeding 
three points under the same accelerating airflow pressure, and only one wheat seed was shot at each point.

\subsubsection{Shooting time}

The pneumatic seeding process was photographed by a high speed camera. The shooting mode was set as capture by frame, the acquisition length was 8000 frames, the acquisition period was $200 \mu \mathrm{s}$, and the exposure time was $100 \mu \mathrm{s}$. Based on the above setting parameters, the actual frame rate $\left(F_{P S}\right)$ of the high-speed camera was 3862 frames per second according to the software interface of the high-speed camera in high-speed acquisition mode. At the end of each point pneumatic seeding experiment, pictures of a single pneumatic seeding process were extracted from 8000 pictures. The shooting time was calculated by the following equation:

$$
T_{S i j k}=\left(N_{S i j k}-1\right) \frac{1 \times 10^{6}}{F_{P S}}
$$

where, $T_{S i j k}$ is the shooting time of group $j$ point $k$ at level $i, \mathrm{~s} ; N_{S i j k}$ is the number of pictures of single pneumatic seeding process of group $j$ point $k$ at level $i ; N_{S i j k}$ is the actual frame rate of the high speed camera, fps.

\subsubsection{Shooting velocity}

The shooting height $\left(H_{G}\right)$ is $80 \pm 5 \mathrm{~mm}$ in all experiments, and the actual shooting height $\left(H_{G i j k}\right)$ of each pneumatic seeding experiment was measured by electronic digital caliper before each point pneumatic seeding experiment in order to reduce the error and improve the test accuracy. At the same time, considering the very short shooting time of wheat seed, as well as the turbulent jet characteristics of high-speed airflow ejected from the bottom of the accelerating tube ${ }^{[19,20]}$, the pneumatic seeding process of wheat seed was regarded as uniform shooting. The shooting velocity was calculated by the following equation:

$$
v_{S i j}=\frac{1}{3} \cdot \sum_{k=1}^{3} \frac{1000 H_{G i j k}}{T_{S i j k}}
$$

where, $v_{S i j}$ is the average shooting velocity of group $j$ at level $i, \mathrm{~m} / \mathrm{s}$; $H_{G i j k}$ is the actual shooting height of group $j$ point $k$ at level $i, \mathrm{~mm}$.

2.4.3 Shooting depth

The shooting depth, no more than $50 \mathrm{~mm}$ according to agronomic requirements ${ }^{[14,15]}$, is that the vertical distance between the bottom of the seed hole formed by the high-speed impact of wheat and the soil surface. After the pneumatic seeding experiment at each soil moisture content level, the shooting depth of the wheat seed of each point was measured. The shooting depth was calculated by the following equation:

$$
H_{S i j}=\frac{1}{3} \cdot \sum_{k=1}^{3} H_{S i j k}
$$

where, $H_{S i j}$ is the average shooting depth of group $j$ at level $i, \mathrm{~mm}$; $H_{S i j k}$ is the shooting depth of group $j$ point $k$ at level $i, \mathrm{~mm}$.

2.4.4 Seed damage rate

Referring to China National Standard GB/T 9478-2005 "Testing methods of sowing in lines"[21] and GB/T 6973-2005 "Testing methods of single seeding drills (precision drills)",[22], wheat seeds were collected after experiment, then the damaged seeds were selected and counted to calculate the damage rate of seeds as follows:

$$
P=\left(\frac{P_{S}}{P_{Z}}-P_{Y}\right) \times 100 \%
$$

where, $P$ is seed damage rate, $\% ; P_{S}$ is the number of damaged seeds in the pneumatic seeding experiment; $P_{Z}$ is the total number of seeds in the pneumatic seeding experiment; $P_{Y}$ is the initial seed damage rate, $\%$.

\subsection{Data analyses}

Microsoft Excel 2016 and Matlab 2014a were employed to record and analyze experimental data. Sigma 10.0 was used to draw figures and to fit mathematical models.

\section{Results and analyses}

\subsection{Pneumatic seeding effect}

Taking the pneumatic seeding process under the maximum accelerating air pressure (10 bar) and the relative minimum pressure of it (4 bar) as an example, the pneumatic seeding process of wheat seed was shown in Figure 3. It is obvious that wheat seed shows less shooting time and faster shooting velocity under relative higher acceleration pressure. When the accelerating air the pressure is $10 \mathrm{bar}$, the shooting time is $1295 \mu$ s (Figure 3a), which is about $37.5 \%$ lower than that of $2072 \mu$ s under 4 bar accelerating air pressure (Figure $3 b$ ). Besides, in the first group of
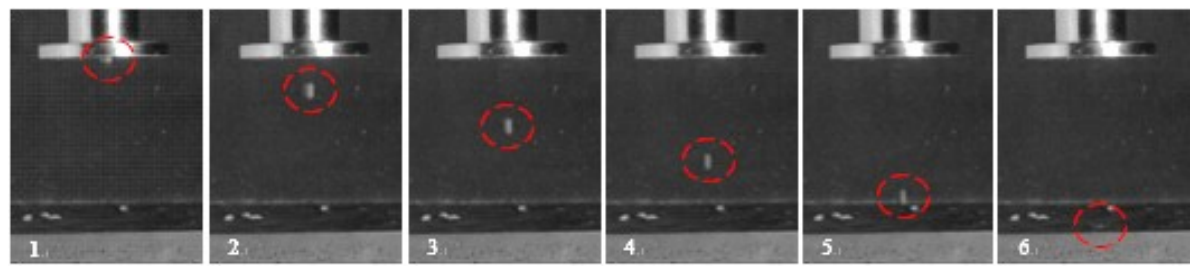

a. Higher speed pneumatic seeding (30\% soil moisture content, 10 bar accelerating air pressure, $8 \mathrm{~cm}$ actual shooting height)
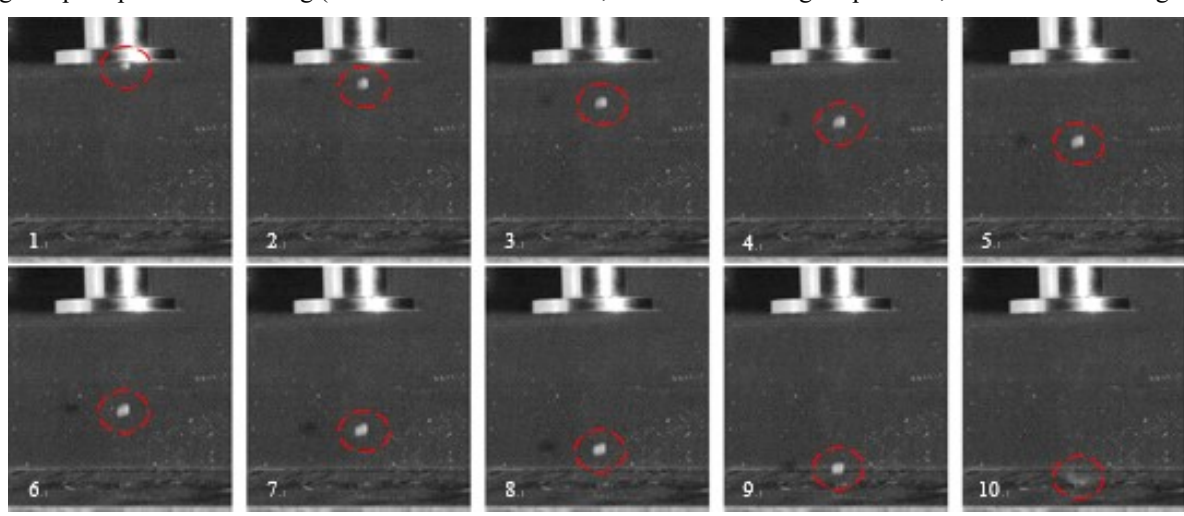

b. Lower speed pneumatic seeding ( $45 \%$ soil moisture content, 4 bar accelerating air pressure, $8 \mathrm{~cm}$ actual shooting height)

Figure 3 Procedure example of wheat pneumatic seeding 
pneumatic seeding experiments with different soil moisture levels, all the wheat seeds are shoot after the free-fall acceleration with accelerated air pressure zero. No wheat seed is ripped into the soil. Among them, when the soil moisture content was $30 \%$ and $35 \%$, different degrees of rebound will happen when the wheat seeds hit the soil, while there were no bouncing phenomena if the soil moisture content was $40 \%, 45 \%$ or $50 \%$.

Figure 4 shows the pneumatic seeding effect of wheat seeds at five different soil moisture levels. It could be seen that there were evident differences in shooting depth and soil impact effect of wheat seeds for each group under different accelerating air pressures, and it was observed that there no damage occurred to wheat seeds through ways of pneumatic seeding. Moreover, the soil structure in the non-sown area remains relatively intact overall, despite small seed holes are formed when the wheat seeds were ripped into the soil. This is the case even if the higher pressure of accelerating airflow would destroy the soil layer with high water content (group VI of Figure 4c, group VI of Figure 4d, group V and VI of Figure 4e). Therefore, compared with traditional wheat rotary tillage planting machinery, pneumatic seeding technology is conducive to reduce soil disturbance in the sowing stage.

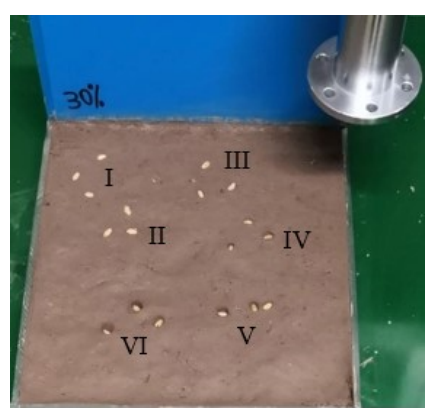

a. $30 \%$ soil moisture content

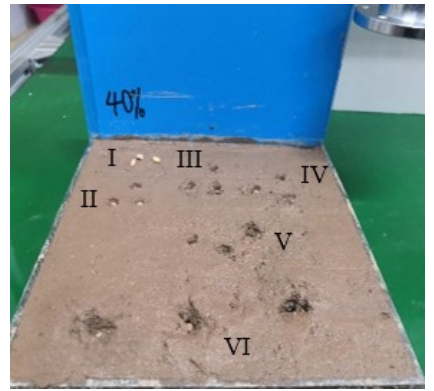

c. $40 \%$ soil moisture content

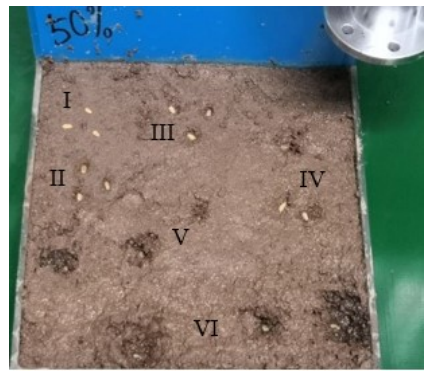

e. $50 \%$ soil moisture content

Note: I, II, III, IV, V, VI are the numbers of each group of wheat seeds pneumatic seeding experiment.

Figure 4 Pneumatic seeding effect of wheat seeds under different levels of soil moisture content

\subsection{Regression relationship}

The results of wheat pneumatic seeding experiments underdifferent soil moisture content are shown in Table 1.
Table 1 Results of wheat pneumatic seeding under different levels of soil moisture content

\begin{tabular}{|c|c|c|c|}
\hline $\begin{array}{l}\text { Soil moisture } \\
\text { content } / \%\end{array}$ & $\begin{array}{l}\text { Accelerating } \\
\text { pressure/bar }\end{array}$ & $\begin{array}{l}\text { Shooting velocity } \\
\qquad / \mathrm{m} \cdot \mathrm{s}^{-1}\end{array}$ & $\begin{array}{l}\text { Shooting depth } \\
/ \mathrm{mm}\end{array}$ \\
\hline \multirow{6}{*}{30} & 0 & 3.06 & 0 \\
\hline & 2 & 25.15 & 1.75 \\
\hline & 4 & 36.94 & 2.60 \\
\hline & 6 & 44.13 & 3.60 \\
\hline & 8 & 63.49 & 4.34 \\
\hline & 10 & 72.07 & 7.14 \\
\hline \multirow{6}{*}{35} & 0 & 3.10 & 0 \\
\hline & 2 & 25.35 & 1.83 \\
\hline & 4 & 35.78 & 3.82 \\
\hline & 6 & 44.93 & 4.60 \\
\hline & 8 & 58.35 & 5.98 \\
\hline & 10 & 71.11 & 8.07 \\
\hline \multirow{6}{*}{40} & 0 & 2.82 & 0 \\
\hline & 2 & 27.45 & 4.25 \\
\hline & 4 & 37.88 & 7.35 \\
\hline & 6 & 44.13 & 9.14 \\
\hline & 8 & 51.49 & 10.27 \\
\hline & 10 & 58.34 & 14.89 \\
\hline \multirow{6}{*}{45} & 0 & 2.50 & 0 \\
\hline & 2 & 27.48 & 6.56 \\
\hline & 4 & 37.99 & 8.84 \\
\hline & 6 & 42.97 & 11.85 \\
\hline & 8 & 49.49 & 12.04 \\
\hline & 10 & 55.74 & 15.19 \\
\hline \multirow{6}{*}{50} & 0 & 3.18 & 0 \\
\hline & 2 & 18.27 & 4.70 \\
\hline & 4 & 23.00 & 7.61 \\
\hline & 6 & 30.30 & 12.13 \\
\hline & 8 & 37.99 & 18.66 \\
\hline & 10 & 40.24 & 27.75 \\
\hline
\end{tabular}

The best regression between shooting velocity and shooting depth, under different soil moisture levels, were all $3^{\text {rd }}$ order polynomial regression relation ${ }^{[23-25]}$ as illustrated in Figure 5. The lines represent the regression between shooting velocity and shooting depth. Overall, the shooting depth keeps a deepening tendency with the increase in shooting velocity, and the value of seeding depth and seeding velocity are closely related to the soil moisture level. With the increasing of soil moisture content, wheat seeds could achieve relatively deep shooting depth at relatively low shooting velocity, for instance, wheat seeds could be shot into the soil, $30 \%$ soil moisture content, $7.14 \mathrm{~mm}$ deep at $72.07 \mathrm{~m} / \mathrm{s}$ shooting velocity in group VI, while they can achieve $7.61 \mathrm{~mm}$ (about $6.6 \%$ deeper than $7.14 \mathrm{~mm}$ ) shooting depth with only $23.00 \mathrm{~m} / \mathrm{s}$ (about $68 \%$ lower than $72.07 \mathrm{~m} / \mathrm{s}$ ) shooting velocity in group III of $50 \%$ soil moisture content, which proves that the increasing of soil moisture is beneficial to pneumatic seeding of wheat seeds into soil. In addition, for experiments on five different soil moisture levels: the shooting velocity is $2.93 \mathrm{~m} / \mathrm{s}$ when wheat seeds accelerated as free falling body and the shooting depth of it was $0 \mathrm{~mm}$, which wheat seeds could not be ripped into soil; statistic of pneumatic seeding results found that the shooting depth of wheat seed just meet exactly ripped into soil was about $3 \mathrm{~mm}$, and the shooting velocity of each levels had evident difference that were $40-50 \mathrm{~m} / \mathrm{s}$ (30\% soil moisture content), 30 $40 \mathrm{~m} / \mathrm{s}$ (35\% soil moisture content), $20-30 \mathrm{~m} / \mathrm{s}$ (40\% soil moisture 
content), $10-20 \mathrm{~m} / \mathrm{s}$ (45\% soil moisture content), $2.93-10 \mathrm{~m} / \mathrm{s}(50 \%$

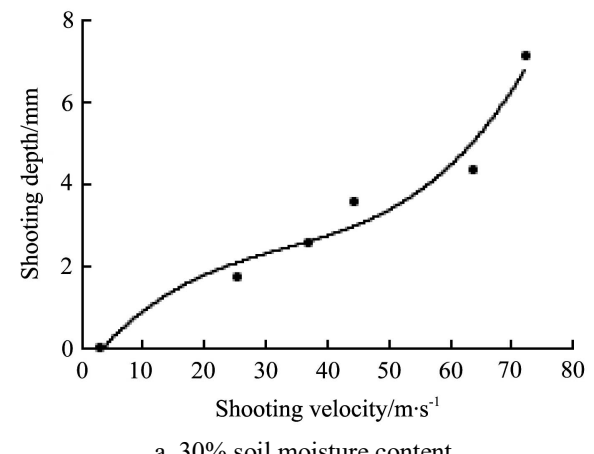

a. $30 \%$ soil moisture content

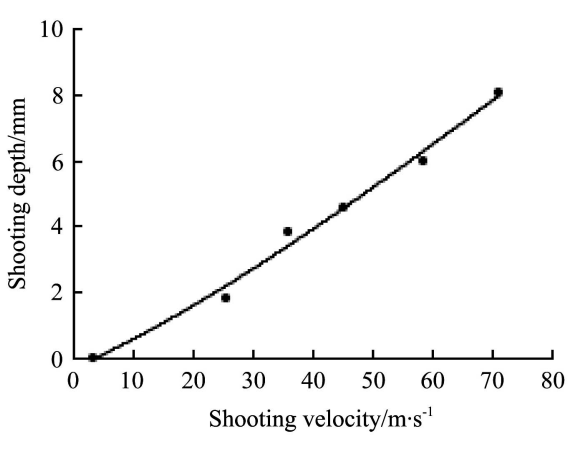

b. $35 \%$ soil moisture content

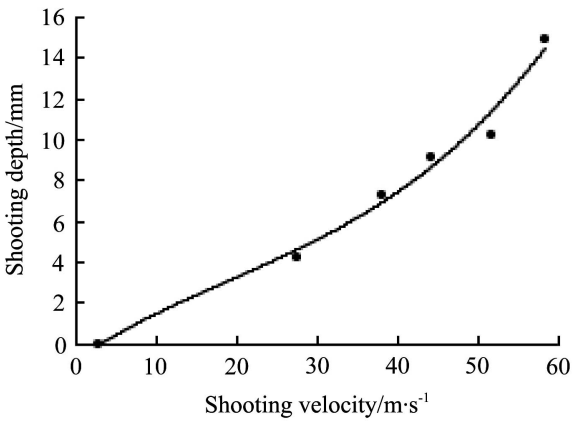

c. $40 \%$ soil moisture content

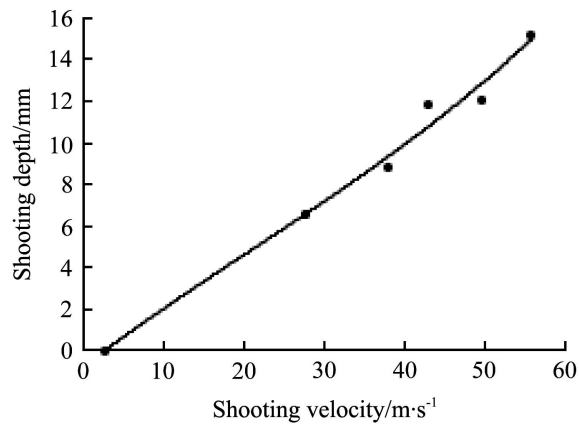

d. $45 \%$ soil moisture content

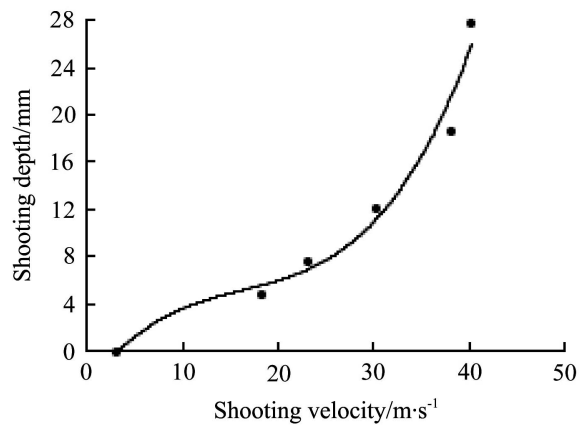

e. $50 \%$ soil moisture content

Figure 5 Regression between shooting velocity and shooting depth under different levels of soil moisture content

Shooting velocity and shooting depth are expressed with $x$ and $y$ separately, the fitting equation and $R^{2}$ value of fitting relationship curve above are listed in Table 2. As can be seen from Table 2, the determination fitting parameters vary from 0.9638 to 0.9903 with a good correlation ${ }^{[26-28]}$

\section{Table 2 Regression equation and $\boldsymbol{R}^{2}$ for each level pneumatic} seeding experiment

\begin{tabular}{clc}
\hline Soil moisture content & \multicolumn{1}{c}{ Fitting equation } & $R^{2}$ \\
\hline $30 \%$ & $y=5 \times 10^{-5} x^{3}-0.0046 x^{2}+0.1931 x-0.6177$ & 0.9638 \\
$35 \%$ & $y=-3 \times 10^{-6} x^{3}+0.0007 x^{2}+0.0827 x-0.3108$ & 0.9903 \\
$40 \%$ & $y=7 \times 10^{-5} x^{3}-0.0043 x^{2}+0.2555 x-0.7025$ & 0.9861 \\
$45 \%$ & $y=3 \times 10^{-5} x^{3}-0.0019 x^{2}+0.2937 x-0.728$ & 0.9856 \\
$50 \%$ & $y=0.0012 x^{3}-0.0562 x^{2}+1.1175 x-3.1125$ & 0.9745 \\
\hline
\end{tabular}

It can be seen from Figures $5 \mathrm{a}$ and $5 \mathrm{~b}$ that shooting depth of $35 \%$ soil moisture content increased rapidly compared with that of $30 \%$ soil moisture content along with the increased of shooting velocity. When shooting velocity was $44.13 \mathrm{~m} / \mathrm{s}$, wheat seeds ripped into the soil $3.60 \mathrm{~mm}$ deep under the condition of $30 \%$ soil moisture content (as shown in Figure 4a, group IV), while increased shooting depth by about $27 \%$ with the same shooting velocity for $35 \%$ soil moisture level. Maximum shooting velocity value of $71.59 \mathrm{~m} / \mathrm{s}$ obtained as accelerating airflow pressure reached the maximum value of 10 bar, under which wheat seeds got maximum shooting depth value of $7.14 \mathrm{~mm}$ (30\% soil moisture content) and $8.07 \mathrm{~mm}$ (35\% soil moisture content) respectively. Furthermore, the shooting depth is about $14.89 \mathrm{~mm}$ (Figure 5c) that was $109 \%$ and $85 \%$ deeper than the maximum shooting depth at $30 \%$ and $35 \%$ soil moisture content, respectively, realized by $58.34 \mathrm{~m} / \mathrm{s}$ shooting velocity under $40 \%$ soil moisture content.

As can be seen from Figures $5 \mathrm{~d}$ and $5 \mathrm{e}$, the shooting depth increased significantly with the rise of shooting velocity if the soil moisture content is $45 \%$ and $50 \%$. This is possible because that soil water moisture exceeded the liquid limit of soil that changes from plastic state to flowage state ${ }^{[29]}$. Wheat seeds acquired about $3 \mathrm{~mm}$ shooting depth with only $9 \mathrm{~m} / \mathrm{s}$ shooting velocity for the soil of $50 \%$ moisture content, which $13 \mathrm{~m} / \mathrm{s}$ shooting velocity will be needed for the soil of $45 \%$ soil moisture. To group VI of pneumatic seeding experiment, the shooting depth was $15.19 \mathrm{~mm}$ with $\quad 55.74 \mathrm{~m} / \mathrm{s}$ shooting velocity for $45 \%$ soil moisture content and $27.75 \mathrm{~mm}$ depth with $40.24 \mathrm{~m} / \mathrm{s}$ shooting velocity for $50 \%$ soil moisture content, during which the high accelerating airflow will blow off small part of top soil after wheat seed seeded (Figure 4d-e) because of the decreased resistance of soil under excessive moisture content.

\subsection{Germination results}

In order to verify whether pneumatic seeding could cause damage to wheat seeds further, the above experimental process was repeated under the same conditions and the germination results of wheat were observed. The emergence of wheat seedlings was shown in Figure 6 after 10 days at about $20^{\circ} \mathrm{C}$ room temperature.

As shown in Figure 6, varying degrees of germination for wheat seeds were achieved under different pneumatic seeding parameters and soil moisture contents. This is consistent with the zero damage results of wheat seeds in previous experiments and indicates that wheat seeds are sown into the soil by non-contact technology of pneumatic seeding is feasible. Although, there were later emergence phenomena that wheat seeds were just sprouting out under $45 \%$ and $50 \%$ soil moisture content, which may be due to the excessive moisture content of soil. But this preliminary bench experiment is a basic experiment of wheat pneumatic seeding for fine tilled seedbed conditions that without rice straw and stubble mulching, the difference between experimental soil and field soil that contains impurities such as stones, crop roots, soil block, etc, should be considered and corresponding pneumatic seeding equipment for wheat should be developed and seeding experiments be carried out to observe and evaluate the effects of pneumatic seeding methods on wheat seedling emergence, growth and yield. Moreover, preliminary 
bench experiments of wheat pneumatic seeding under different soil compactness conditions should also be studied, furtherly, to provide basic data for the development of wheat pneumatic seeding equipment.

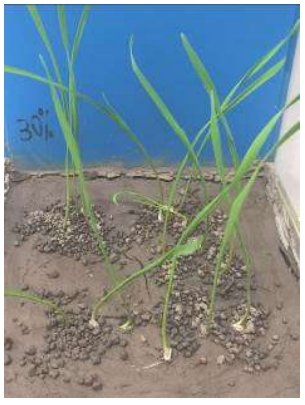

a. $30 \%$ soil moisture content

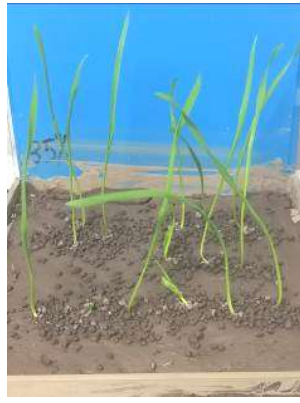

b. $35 \%$ soil moisture content

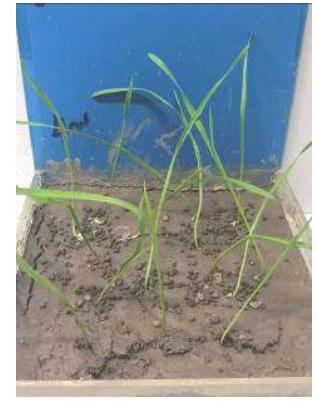

c. $40 \%$ soil moisture content

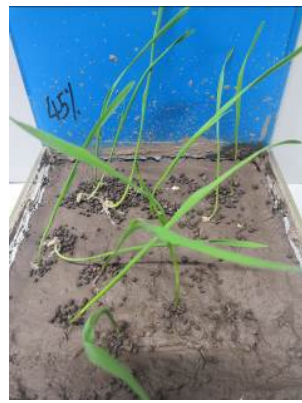

d. $45 \%$ soil moisture content

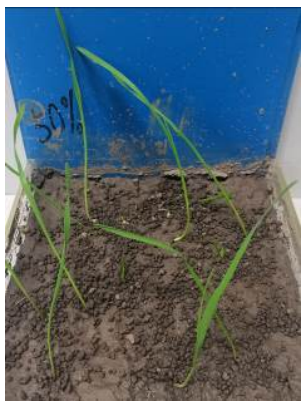

e. $50 \%$ soil moisture content

Figure 6 Germination results of pneumatic seeding under different levels of soil moisture content

\section{Conclusions}

In this research, a non-contact technology of pneumatic seeding was introduced, which directed at solving the problems of serious adhesion and blockage as well as high operating resistance for wheat seeders under the condition of sticky heavy loam clay in rice-wheat rotation area. In this technique, wheat seeds were accelerated by high pressure accelerating airflow and ripped into the soil with a certain shooting speed through a pneumatic seeding mechanism. Preliminary bench experiments have shown that wheat seeds could be shot into the soil without damage and acquired varying degrees of germination by way of pneumatic seeding.

High-speed photography of wheat pneumatic seeding of five different soil moisture levels illustrated that wheat seeds could not be ripped into soil with free falling acceleration that the shooting speed was about $2.93 \mathrm{~m} / \mathrm{s}$, while as the shooting velocity were $40-50 \mathrm{~m} / \mathrm{s}$ (30\% soil moisture content), $30-40 \mathrm{~m} / \mathrm{s}$ (35\% soil moisture content), $20-30 \mathrm{~m} / \mathrm{s}$ ( $40 \%$ soil moisture content), $10-$ $20 \mathrm{~m} / \mathrm{s}$ (45\% soil moisture content), $2.93-10 \mathrm{~m} / \mathrm{s} \quad(50 \%$ soil moisture content), respectively, wheat seed could just exactly be ripped into soil with about $3 \mathrm{~mm}$ depth. Meanwhile, the shooting depth kept a deepening tendency with the increase in shooting velocity, and the value of seeding depth and seeding velocity are closely related to the soil moisture level. In other words, wheat seeds can achieve higher shooting depth with relative lower shooting velocity when the soil moisture content increases continuously.

Since the study is a basic experiment under fine tilled seedbed conditions that without mulching of rice straw and stubble mulching, as well as impurities such as stones, crop roots, soil block, etc, further study that pneumatic seeding under different soil compactness conditions and growth results of field experiments by this technology is still needed.

\section{Acknowledgements}

This paper was funded by the Program for China Agriculture Research System (CARS-03) and Changjiang Scholars, Innovative Research Team in University of China (Grant No. IRT13039). Gratitude should be expressed to all the members of Conservation Tillage Research Centre.

\section{[References]}

[1] Ma L, Yang L Z, Shen M X, Xia L Z, Li Y D, Liu G H, et al. Study on crop yield stability in a typical region of rice-wheat rotation based on long-term fertilization experiment. Transaction of the CSAE, 2011; 27(4): 117-124. (in Chinese)
[2] Qiu R J, Yang Z Q, Jing Y S, Liu C W, Wang Z C. Analysis of water and heat flux over rice-wheat rotation field and influencing factors. Transactions of the CSAE, 2018; 34(17): 82-88. (in Chinese)

[3] Qi J, Herman V K, Huib H. Modeling biomass, nitrogen and water dynamics in rice-wheat rotations. Agricultural Systems, 2010; 103(7): 433-443.

[4] Zhang X M, Zhang J M, Xia J F, Zhang S, Li J B, Wu H. Design and experiment on critical component of cultivator for straw returning in paddy field and dry land. Transaction of the CSAE, 2015; 31(11): 10-16. (in Chinese)

[5] Gu F W, Gao X M, Wu F, Hu Z C, Chen Y Q, Zhang C. Improvement of uniform scattering device for straw-smashing, back-throwing, no-tillage planter under complete straw mulching condition. Int J Agric \& Biol Eng, 2018; 11(6): 49-57

[6] Liu S P, Chen H Q, Nie X T, Dai Q G, Huo Z Y, Xu K, et al. Comprehensive evaluation of tillage and straw returning on soil fertility in a wheat-rice double cropping system. Transactions of the CSAE, 2008; 24(5): 51-56.

[7] Zhu H B. Study on anti-blocking device of no-till wheat planter for broken and crushing rice crop stubble. Beijing: China Agricultural University, 2013. (in Chinese)

[8] Tang Y L, Huang G, Yuan L X. High-benefit cultivation technique of surface seeding and mulching rice straw for wheat after rice. Crops, 2000 3: $22-24$.

[9] Zhao G C. Ecology characteristics of Chinese wheat planting region. Journal of Triticeae Crops, 2010; 30(4): 684-686.

[10] He J, Zhang Z Q, Li H W, Wang Q J. Development of small/medium size no-till and minimum-till seeders in Asia: A review. Int $\mathrm{J}$ Agric \& Biol Eng, 2014; 7(4): 1-12.

[11] Sidhu H S, Singh M, Humphreys E, Humphreys E, Singh Y, Singh B, et al The happy seeder enables direct drilling of wheat into rice stubble. Australian Journal of Experimental Agriculture, 2007; 47(7): 844-854.

[12] Pannu C J S, Shukla L N. Tractor front-mounted cross-conveyor paddy straw thrower. AMA-Agricultural Mechanization in Asia Africa and Latin America, 2010; 41(2): 35-42.

[13] Li B, Wang J X, Zhang J M, Xia P, Xu W J. Design of GBSL-180 seeder with two-axel rotary tillage and stubble cleaning. Transactions of the CSAE, 2008; 39(3): 180-182. (in Chinese)

[14] Li C S, Tang Y L, Xie L S, Huang G, Zhong G X, Wu C, et al. Design and experiment of 2BMFDC- 6 half-tillage seeder of wheat after rice. Southwest China Journal of Agricultural Sciences, 2011; 24(2): 789-793.

[15] Li C S, Tang Y L, Wu C, Huang G. Effect of sowing patterns on growth, development and yield formation of wheat in rice stubble land. Transactions of the CSAE, 2012; 28(18): 36-43.

[16] Ladha J K, Dawe D, Pathak H, Padre A T, Yadav R L, Singh B, et al. How extensive are yield declines in long-term rice-wheat experiments in Asia? Field Crops Research, 2003; 81(2): 159-180.

[17] Ma L, Yang L Z, Shen M X, Xia L Z, Li Y D, Liu G H, et al. Study on crop yield stability in a typical region of rice-wheat rotation based on long-term fertilization experiment. Transactions of the CSAE, 2011; 27(4): 117-124.

[18] GB/T50123-1999 Standard for Soil Test Method. Beijing: China Planning Press, 1999.

[19] Xie J, Liu Y Y, Wang J F. Effects of nozzle structures of air impinging freezer on heat transfer characteristics of steel strip surface. Transactions of the CSAE, 2018; 34(18): 292-298. (in Chinese) 
[20] Wang C, Zhu J B, Hu B. Suction Performance and Energy Dissipation Characteristics of Annular Submerged Jets. Transactions of the CSAM, 2016; 47(8): 14-21, 13. (in Chinese)

[21] GB/T 9478-2005 Testing methods of sowing in lines. Beijing: Standards Press of China, 2005. (in Chinese)

[22] GB/T 6973-2005 Testing methods of single seed drills (precision drills). Beijing: Standards Press of China, 2005.

[23] Zhang Z T, Lan Y, Wu P T, Han W T. Model of soybean NDVI change based on time series. Int J Agric \& Biol Eng, 2014; 7(5): 64-70.

[24] Lei X L, Liao Y T, Cong J L, Wang L, Zhang Q S, Liao Q X. Parameter optimization and experiment of air-assisted centralized seed-metering device of direct seeding machine for rape and wheat. Transactions of the CSAE, 2018; 34(12): 16-26. (in Chinese)

[25] Bunce C. Correlation, agreement, and Bland-Altman analysis: Statistical analysis of method comparison studies. Am J Ophthal, 2009; 148(1): 4-6.

[26] Zhang Q G, Wang Y K, Hu J J, Guo J, Zhang Z P, Jing Y Y, et al Temperature variation of reaction liquid of ultrafine corn stover in photosynthetic hydrogen production. Int J Agric \& Biol Eng, 2014; 7(5): 78-84.

[27] Yang Z M, Sun J X, Guo Y M. Effect of moisture content on compression mechanical properties and frictional characteristics of millet grain. Transactions of the CSAE, 2015; 31(23): 253-260. (in Chinese)

[28] Sun S, Zhang J S, Meng P, Wang G B, Huang H, Yin C J, et al Establishment and application of prediction model of soil water in walnut orchard based on unmanned aerial vehicle thermal infrared imagery. Transactions of the CSAE, 2018; 34(16): 89-95.

[29] Zhang K G, Liu S Y. Soil mechanics. Beijing: China Architecture\& Building Press, 2010. (in Chinese) 